\title{
BLOODSTREAM INFECTION WITH OLIGELLA UREOLYTICA IN INFANT: A CASE REPORT AND REVIEW OF LITERATURE
}

\author{
APOORVA B, ZARINE KHAN, TARANA SARWAT* \\ Department of Microbiology, School of Medical Sciences and Research, Sharda University, Greater Noida, Uttar Pradesh, India. \\ Email: taranasf@gmail.com
}

Received: 28 July 2020, Revised and Accepted: 04 September 2020

\begin{abstract}
Oligella ureolytica is rarely involved as human pathogen but it is emerging as pathogenic bacteria. It is not commonly recovered from clinical specimens but when recovered, it is mostly from urinary and respiratory tract specimens as commensal organisms, but hardly from blood samples. We present here a case of 0 . ureolytica related bacteremia in a 1-month-old infant as a pure culture and we review the literature of previously reported cases of Oligella infections.
\end{abstract}

Keywords: Oligella ureolytica, Bacteremia, CDC Group IVe (Centers for Disease Control and Prevention).

(C) 2020 The Authors. Published by Innovare Academic Sciences Pvt Ltd. This is an open access article under the CC BY license (http://creativecommons. org/licenses/by/4. 0/) DOI: http://dx.doi.org/10.22159/ajpcr.2020.v13i11.39251

\section{INTRODUCTION}

Oligella are Gram-negative, non-fermenting aerobic rods or coccobacilli which are catalase and oxidase positive and hydrolyze urea easily (within minutes after inoculation). The genus Oligella constitutes two species Oligella ureolytica and Oligella urethralis. O. ureolytica, previously known as Centers for Disease Control and Prevention (CDC) Group IVe, is clinically more significant as it related to urinary tract infections and sometimes bacterial infections, but rarely isolated from wounds, septic arthritis, or peritonitis.

\section{CASE REPORT}

A 1 month 10 days old male (weight $3.9 \mathrm{~kg}$ ) was admitted to pediatric intensive care unit, with the symptoms of loose stools (5-6 episodes/day), semi-solid, foul smelling but not associated with blood, multiple episodes of vomiting and loss of consciousness after vomiting for 2-3 min. Respiratory, cardiovascular, and abdominal examination were unremarkable but weakness in newborn reflexes and icterus was observed.

Blood was collected and sent to hematology, microbiology, and biochemistry laboratory for further investigations. Hematological investigation revealed hemoglobin: $11.9 \mathrm{~g} / \mathrm{dL}$, total leukocyte count: $15.15 \times 10^{9} / \mathrm{L}$, differential leukocyte count showed neutrophils $23 \%$, lymphocytes $63 \%$, eosinophils $4 \%$, and monocytes $10 \%$, serum total protein: $5.9 \mathrm{~g} / \mathrm{dL}$, serum albumin: $3.8 \mathrm{~g} / \mathrm{dL}$, and serum globulin: $2.1 \mathrm{~g} / \mathrm{dL}$. Low levels of Red Blood Cells $\left(3.84 \times 10^{6} / \mathrm{mL}\right)$ and high levels of Mean Corpuscular Volume (96.9 fL), Mean Corpuscular Haemoglobin (31 pg), and Mean Corpuscular Haemoglobin Concentration (32 g/dL) were observed. C-reactive protein (Latex) was negative, malarial antigen was negative and no malarial parasite was observed on peripheral smear. Liver function test was also done which showed increase in total serum bilirubin $(2.1 \mathrm{mg} / \mathrm{dL})$, aspartate transaminase (67.2 U/L), and alkaline phosphatase (292 U/L) levels.

Blood culture was performed on BacT/Alert 3D (BioMérieux, Durham, North Carolina, USA). Subcultures were done on nutrient, blood, and MacConkey agar after growth was observed in blood culture bottles. After 2 days of incubation, non-lactose fermenting, orange color colonies were observed on MacConkey agar. On blood agar, the colonies were small, smooth, and non-hemolytic. Orange-colored colonies were also observed on nutrient agar. Microscopy revealed Gram-negative coccobacilli which were oxidase and catalase-positive and it rapidly hydrolyzed urea (Fig. 1). Identification of the isolate was done by VITEK2 compact system (BioMérieux, North Carolina, USA) as o. ureolytica with $97 \%$ probability.

The infant was given an empiric therapy which included cefotaxime injection (Inj.) (200 mg/kg/12 hourly) and amikacin Inj. (60 mg/kg/24 hourly) on admission. As there is no standardized antimicrobial susceptibility pattern for Oligella given by Clinical and Laboratory Standard Institute (CLSI), cutoff values of nonEnterobacteriaceae on CLSI were used for interpretation of susceptibility pattern. The organism was susceptible to gentamicin, amikacin, cefotaxime, ceftazidime, meropenem, and imipenem and was resistant ampicillin, piperacillin, piperacillin-tazobactam, and cotrimoxazole.

\section{DISCUSSION}

Oligella infection has rarely been reported. This may be due to lack of organism's identification by conventional methods or uncertainty of organism's pathogenicity. Oligella spp. have been reported in literatures to be mainly associated with urinary tract infections in patients with indwelling catheters, in cancer patients, found in lymph node, in pleural fluid, decortication tissue of a child with chronic granulomatous disease and pneumonia [1]. A search of the literature published since 1978 on PubMed revealed nine case reports. Table 1 shows the clinical data of the cases reported [2-9].

In this article, we report a case of 0 . ureolytica related to bacteremia in an infant. The patient consent was duly signed by the parents as the patient was a minor. In previous cases, most of the patients were adults with the underlying infection. There was only one report where the organism was isolated from a newborn infant [9]. In our laboratory, Oligella is not frequently isolated and has also never been identified as a contaminant in blood culture bottles or any other clinical samples. In the present case study, $O$. ureolytica was the only organism isolated and the patient also responded to the treatment provided, which supports that this organism was the causative agent of the bacteremia in the infant.

In a study by Baqi and Mazzulliand Welch etal., the isolate was susceptible to amikacin and gentamicin and resistant to serum concentrations of ampicillin and piperacillin similar to our study $[10,11]$. However, Baqi and Mazzulli, Rockhill and Lutwick, and Manian found that Oligella was susceptible to trimethoprim-sulfamethoxazole (TMP-SMX) $[2,5,10]$. 
Table 1: Reports of Oligella spp. infection isolated from various clinical samples

\begin{tabular}{|c|c|c|c|c|c|c|}
\hline Year & Reference & Age (years) & Isolate & Source & Underlying conditions & Outcome \\
\hline 1978 & 2 & 5 & O. ureolytica & Blood, urine & $\begin{array}{l}\text { Uterine adenocarcinoma, } \\
\text { obstructive uropathy }\end{array}$ & Recovered \\
\hline 1992 & 3 & 83 & O. urethralis & Knee fluid & $\begin{array}{l}\text { Rectal adenocarcinoma, } \\
\text { septic arthritis }\end{array}$ & Recovered \\
\hline 1993 & 4 & 75 & O. urethralis & Blood, urine & $\begin{array}{l}\text { Metastatic colorectal cancer, } \\
\text { obstructive uropathy }\end{array}$ & Recovered \\
\hline 1993 & 5 & 40 & O. ureolytica & Blood & AIDS, sacral ulcer, fungemia & $\begin{array}{l}\text { Responded, died } \\
\text { secondary to fungemia }\end{array}$ \\
\hline 1996 & 6 & 45 & O. ureolytica & Lymph node & Lymphoma & Recovered \\
\hline 2001 & 7 & 70 & O. urethralis & Urine & $\begin{array}{l}\text { Bladder operation, chronic } \\
\text { pyelonephritis }\end{array}$ & Recovered \\
\hline 2001 & 8 & 18 months & O. ureolytica & Blood & Pneumoniae & Recovered \\
\hline 2014 & 9 & 24 hours infant & O. ureolytica & Blood & Sepsis & Recovered \\
\hline 2014 & 1 & 30 & O. ureolytica & Blood & $\begin{array}{l}\text { Lung adenocarcinoma, } \\
\text { abdominal lymph } \\
\text { node metastasis with } \\
\text { syringohydromyelia }\end{array}$ & Recovered \\
\hline Present study (2019) & & 1 month & O. ureolytica & Blood & Sepsis & Recovered \\
\hline
\end{tabular}

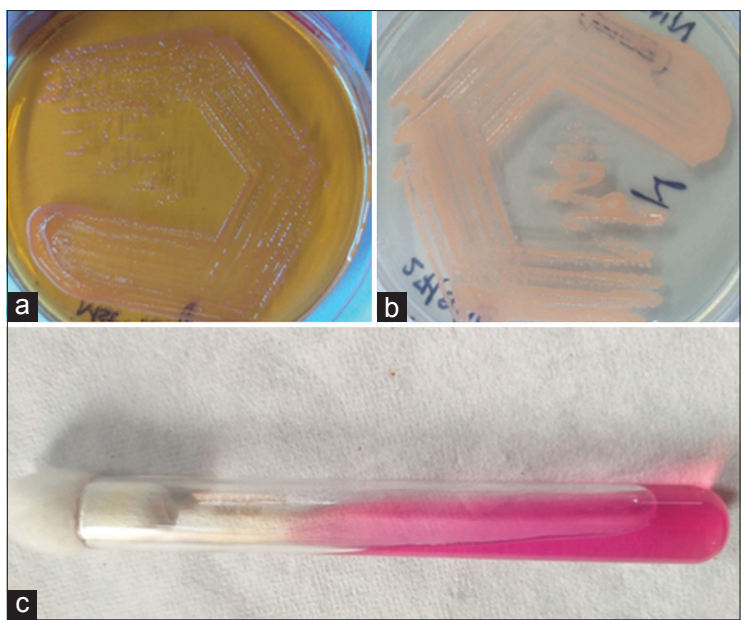

Fig. 1: (a) Colony on MacConkey agar. (b) Colony on nutrient agar. (c) Urease hydrolysis test positive

Lechner and Bruckner found that $O$. ureolytica was highly resistant to TMP-SMX, imipenem, meropenem, and ciprofloxacin [8].

In our patient, the condition improved after the following therapy with inj. amikacin and inj. cefotaxime. The second bottle of blood culture from the patient after the completion of therapy remained sterile.

\section{CONCLUSION}

Oligella infection is not common among the infants and has not be reported in literatures. This may be because of misidentification of the organism. Oligella is usually a commensal organism isolated from the urinary tract, however, in the present study, it was found as the cause of septicemia in an infant which may be because of the infection acquired during the delivery of the baby. Oligella infection may be pathogenic in extreme of age groups as seen in our case report which may have contributed to the infection.

Thus, high microbiological surveillance is required to identify this unusual pathogen and prevent further complications.

\section{AUTHORS' CONTRIBUTIONS}

B. Apoorva made substantial contribution to the conception, acquisition of data, and took part in the drafting the article. Zarine Khan and Tarana Sarwat took part in revising it critically for important intellectual content, final approval of the version to be published.

\section{AUTHORS' FUNDING}

The authors received no specific funding.

\section{CONFLICTS OF INTEREST}

The authors declared that there are no conflicts of interest related to this study.

\section{REFERENCES}

1. Baruah FK, Jain M, Lodha M, Grover RK. Blood stream infection by an emerging pathogen Oligella ureolytica in a cancer patient: Case report and review of literature. Indian J Pathol Microbiol 2014;57:131-3.

2. Rockhill RC, Lutwick LI. Group IVe-like gram-negative bacillemia in a patient with obstructive uropathy. J Clin Microbiol 1978;8:108-9.

3. Mesnard R, Sire JM, Donnio PY, Riou JY, Avril JL. Septic arthritis due to Oligella urethralis. Eur J Clin Microbiol Infect Dis 1992;11:195-6.

4. Pugliese A, Pacris B, Schoch PE, Cunha BA. Oligella urethralis urosepsis. Clin Infect Dis 1993;17:1069-70.

5. Manian FA. Bloodstream infection with Oligella ureolytica, Candida krusei and Bacteriodes species in a patient with AIDS. Clin Infect Dis 1993;17:290-1

6. Riley UB, Bignardi G, Goldberg L, Johanson AP, Holmes B. Quinolon resistance in Oligella urethralis-associated chronic ambulatory peritoneal dialysis peritonitis. J Infect 1996;32:155-6.

7. Mora SE, Trapero CM, Val MG, Calleja AI. Urinary infection caused by Oligella urethralis. Aten Primaria 2001;28:622-3.

8. Lechner A, Bruckner DA. Oligella ureolytica in blood culture: Contaminant or infection? Eur J Clin Microbiol Infect Dis 2001;20:142-3.

9. Tulin D, Nuran C. Bloodstream infection with Oligella ureolytica in a newborn infant: A case report and review of literature. J Infect Dev Ctries 2014;8:793-5.

10. Baqi M, Mazzulli T. Oligella infections: Case report and review of literature. Can J Infect Dis 1996;7:377-9.

11. Welch WD, Porschen RK, Luttrell B. Minimal inhibitory concentation of 19 antimicrobial agents for 96 clinical isolates of group IVe Bacteria. Antimicrob Agents Chemother 1983;24:432-3. 